\title{
The Relationship between Resistance Exercise Performance and Ventilatory Efficiency after Beetroot Juice Intake in Well-Trained Athletes
}

\author{
Noemí Serra-Payá ${ }^{1}$ (D), Manuel Vicente Garnacho-Castaño ${ }^{1, *,+} \mathbb{D}$, Sergio Sánchez-Nuño ${ }^{1,+} \mathbf{D}^{(\mathbb{D})}$, \\ Lluís Albesa-Albiol ${ }^{1}{ }^{1}$, Montserrat Girabent-Farrés ${ }^{1}$, Luciana Moizé Arcone ${ }^{1}$, Alba Pardo Fernández ${ }^{1}$, \\ Adrián García-Fresneda ${ }^{1}$, Jorge Castizo-Olier ${ }^{1}{ }^{1}$, Xavier Viñals ${ }^{1}$, Lorena Molina-Raya ${ }^{2}$ \\ and Manuel Gomis Bataller 1
}

1 School of Health Sciences, TecnoCampus Pompeu Fabra University, Ernest Lluch, 32 (Porta Laietana), 08302 Mataró-Barcelona, Spain; nserra@tecnocampus.cat (N.S.-P.); ssanchezn@tecnocampus.cat (S.S.-N.); lalbesa@tecnocampus.cat (L.A.-A.); mgirabent@tecnocampus.cat (M.G.-F.); lmoize@tecnocampus.cat (L.M.A.); apardo@tecnocampus.cat (A.P.F.); agarciaf@tecnocampus.cat (A.G.-F.); jcastizo@tecnocampus.cat (J.C.-O.); xvinals@tecnocampus.cat (X.V.); mgomis@tecnocampus.cat (M.G.B.)

2 Campus Docent Sant Joan de Déu, Fundación Privada, 08304 Barcelona, Spain; lmolina@santjoandedeu.edu.es

check for updates

Citation: Serra-Payá, N.;

Garnacho-Castaño, M.V.;

Sánchez-Nuño, S.; Albesa-Albiol, L.; Girabent-Farrés, M.; Moizé Arcone, L.; Fernández, A.P.; García-Fresneda, A.; Castizo-Olier, J.; Viñals, X.; et al. The Relationship between Resistance Exercise Performance and Ventilatory Efficiency after Beetroot Juice Intake in Well-Trained Athletes. Nutrients 2021, 13, 1094. https://doi.org/ $10.3390 /$ nu13041094

Academic Editors: David Lee Hamilton and Louise Deldicque

Received: 7 February 2021

Accepted: 25 March 2021

Published: 27 March 2021

Publisher's Note: MDPI stays neutral with regard to jurisdictional claims in published maps and institutional affiliations.

Copyright: (c) 2021 by the authors. Licensee MDPI, Basel, Switzerland. This article is an open access article distributed under the terms and conditions of the Creative Commons Attribution (CC BY) license (https:/ / creativecommons.org/licenses/by/ $4.0 /)$.
* Correspondence: mgarnacho@escs.tecnocampus.cat; Tel.: +34-606275392

$\dagger$ These authors contributed equally to this work.

Abstract: The assessment of ventilatory efficiency is critical to understanding the matching of ventilation (VE) and perfusion in the lungs during exercise. This study aimed to establish a causal physiological relationship between ventilatory efficiency and resistance exercise performance after beetroot juice (BJ) intake. Eleven well-trained males performed a resistance exercise test after drinking $140 \mathrm{~mL}$ of BJ $\left(\sim 12.8 \mathrm{mmol} \mathrm{NO}_{3}{ }^{-}\right)$or a placebo (PL). Ventilatory efficiency was assessed by the $\mathrm{VE} \bullet \mathrm{VCO}_{2}{ }^{-1}$ slope, the oxygen uptake efficiency slope and the partial pressure of end-tidal carbon dioxide $\left(\mathrm{PetCO}_{2}\right)$. The two experimental conditions were controlled using a randomized, double-blind crossover design. The resistance exercise test involved repeating the same routine twice, which consisted of wall ball shots plus a full squat (FS) with a 3 min rest or without a rest between the two exercises. A higher weight lifted was detected in the FS exercise after BJ intake compared with the PL during the first routine $(p=0.004)$. $\mathrm{BJ}$ improved the $\mathrm{VE} \bullet \mathrm{VCO}_{2}{ }^{-1}$ slope and the $\mathrm{PetCO} \mathrm{CO}_{2}$ during the $\mathrm{FS}$ exercise in the first routine and at rest $(p<0.05)$. $\mathrm{BJ}$ intake improved the $\mathrm{VE} \bullet \mathrm{VCO}_{2}{ }^{-1}$ slope and the $\mathrm{PetCO}_{2}$ coinciding with the resistance exercise performance. The ergogenic effect of $\mathrm{BJ}$ could be induced under aerobic conditions at rest.

Keywords: $\mathrm{VE} \bullet \mathrm{VCO}_{2}{ }^{-1}$ slope; oxygen uptake efficiency slope; partial pressure of end-tidal carbon dioxide; nitric oxide; nitrate; nitrite

\section{Introduction}

The assessment of ventilatory efficiency is critical to understanding the matching of ventilation (VE) and perfusion in the lungs. Increased VE/perfusion mismatching induces a steepened inefficiency of the pulmonary gas exchange. In this regard, an increase in VE occurs for a given production of carbon dioxide $\left(\mathrm{VCO}_{2}\right)$ and arterial partial pressure of $\mathrm{CO}_{2}\left(\mathrm{PCO}_{2}\right)$ essentially contributing to hyperpnea and dyspnea [1].

During high intensity exercise, the enhancement of $\mathrm{VE}$ and the removal $\mathrm{VCO}_{2}$ are crucial for the homeostatic control of the $\mathrm{pH}$ [2] and arterial hypoxemia [3] induced by lactic acidosis [4]. It has been widely reported that high intensity exercise reduces the efficiency of the pulmonary gas exchange [5,6] resulting in an augmented VE/perfusion mismatching [7]. The aggravated VE/perfusion during exercise could affect the perfusion of the limb locomotor muscle, reducing exercise tolerance [2]. 
Ventilatory efficiency is commonly assessed by determining the slope of the linear relationship between $\mathrm{VE}$ and $\mathrm{VCO}_{2}\left(\mathrm{VE} \bullet \mathrm{VCO}_{2}{ }^{-1}\right.$ slope $)[8,9]$ and the oxygen uptake efficiency slope (OUES) [10]. The OUES is defined as the rate of the increase of oxygen uptake $\left(\mathrm{VO}_{2}\right)$ in response to $\mathrm{VE}$ during exercise and reflects the efficiency of the extraction and introduction of oxygen into the body [10]. The $\mathrm{VE} \bullet \mathrm{VCO}_{2}{ }^{-1}$ slope is considered to be a gold standard method in pathological events [11] and the OUES is actually used to predict mortality and ventilatory inefficiency in cardiorespiratory disease [12-16] and to determine exercise tolerance [12,17]. In addition, the partial pressure of end-tidal carbon dioxide $\left(\mathrm{PetCO}_{2}\right)$ is a noninvasive and suitable marker for assessing the $\mathrm{VE} /$ perfusion relationship and ventilatory efficiency particularly in cardiac and lung diseases [18-20].

The $\mathrm{VE} \bullet \mathrm{VCO}_{2}{ }^{-1}$ slope and the OUES have been used to a lesser extent for assessing ventilatory efficiency in physically active and healthy people [8] and in highly trained athletes in more endurance-type exercises [2]. The role of the $\mathrm{VE} \bullet \mathrm{VCO}_{2}{ }^{-1}$ slope and the OUES for exercise performance is unclear [2,21]. In addition, ventilatory efficiency is conditioned by the type of exercise test [8], gender and the fitness of the participants [22].

The assessment of ventilatory efficiency is not a common procedure during resistance exercise. Recently, our research group demonstrated that ventilatory efficiency, assessed by the $\mathrm{VE} \bullet \mathrm{VCO}_{2}{ }^{-1}$ slope and the OUES, was similar between a cycle ergometer and a half-squat exercise at the same metabolic intensity in a predominantly aerobic pathway [23]. The $\mathrm{VE} \bullet \mathrm{VCO}_{2}{ }^{-1}$ slope and the OUES during high intensity resistance exercises in a mainly anaerobic metabolism remain unknown. It is plausible to propose a marked ventilatory inefficiency under an environment of low oxygen availability and high blood lactate concentrations during high intensity resistance exercise as occurs in endurance exercise [7]. However, no attention has been paid to the assessment of the $\mathrm{VE} \bullet \mathrm{VCO}_{2}{ }^{-1}$ slope and the OUES in well-trained resistance training practitioners during high intensity resistance exercise.

Nitric oxide (NO) is a gaseous signaling molecule that plays a key role in lung physiology [24]. Exogenous NO precursors (sildenafil, L-arginine, inhaled NO, beetroot juice (BJ)) have been used for improving ventilatory efficiency in cardiovascular and respiratory diseases [25-28]. The mechanisms of clinical improvement were related, at least in part, to improvements in pulmonary vasodilation $[29,30]$, pulmonary blood flow and more uniform $\mathrm{VE} /$ perfusion matching [20]. It not usual to assess the effects of exogenous NO precursors on ventilatory efficiency (the $\mathrm{VE} \bullet \mathrm{VCO}_{2}{ }^{-1}$ slope and the OUES) in well-trained athletes.

Concretely, BJ has been demonstrated to improve exercise efficiency [31], lung function and performance during cardiopulmonary exercise testing (CPET) in more endurance-type exercises through the nitrate $\left(\mathrm{NO}_{3}{ }^{-}\right)$to nitrite $\left(\mathrm{NO}_{2}{ }^{-}\right)$conversion pathway [32]. In many cases, improvements in the lung function after BJ intake are often not associated with improvements in endurance performance essentially in well-trained athletes [33]. Recently, we demonstrated that $\mathrm{BJ}$ increased anaerobic performance only after the recovery time between exercises during a high intensity resistance exercise test in well-trained athletes. We also observed that BJ did not improve performance compared with the placebo group when anaerobic conditions were increased with no rest between resistance exercises [34]. The effects of $\mathrm{BJ}$ on the performance of well-trained athletes led to discrepancies among researchers. If exogenous NO precursors improve pulmonary blood flow and more uniform $\mathrm{VE} /$ perfusion matches [20] and high intensity exercise contributes to impaired ventilatory efficiency [7], it is likely that drinks such as BJ could induce an enhancement in performance by improving ventilatory efficiency when a rest is established between resistance exercises. To the best of our knowledge, no studies have assessed the relationship between ventilatory efficiency $\left(\mathrm{VE} \bullet \mathrm{VCO}_{2}{ }^{-1}\right.$ slope and OUES) and high intensity resistance exercise performance in well-trained athletes after BJ intake.

This study aimed to establish a causal physiological association between ventilatory efficiency $\left(\mathrm{VE} \bullet \mathrm{VCO}_{2}{ }^{-1}\right.$ slope and OUES), the $\mathrm{PetCO}_{2}$ and high intensity resistance exercise performance after acute $\mathrm{BJ}$ intake. Bearing in mind that high intensity exercise reduces the efficiency of the pulmonary gas exchange $[5,6]$ resulting in an increased VE-perfusion 
mismatch [7], we hypothesize that NO via dietary BJ could contribute, at least in part, to delaying fatigue and increasing exercise tolerance by improving the $\mathrm{VE} \bullet \mathrm{VCO}_{2}{ }^{-1}$ slope, the OUES and the PetCO $\mathrm{O}_{2}$ when a rest is established between resistance exercises.

\section{Materials and Methods}

\subsection{Study Design}

Participants were required to visit the Fitness Center and Exercise Physiology laboratory in four sessions over three weeks.

In session 1, the experimental procedures were clarified to the participants. During the second session, participants carried out a one-repetition maximum (1RM) test of a full squat (FS) exercise (see below for details). Both sessions were performed in the Fitness Center during the first week.

In sessions 3 and 4 (next two weeks), the two experimental conditions, BJ and the placebo (PL), were compared at the same time of day ( $\pm 30 \mathrm{~min})$ and under similar ambiental conditions (temperature $\sim 22{ }^{\circ} \mathrm{C}$, relative humidity $\sim 50 \%$ ). A one-week washout period was established between both sessions. For this purpose, the participants repeated the same resistance exercise test twice. BJ and the PL were administered three hours before the resistance exercise test in a randomized, double-blind, crossover design. Participants were completely familiarized with the resistance exercises.

Three hours after the BJ or PL ingestion, blood was drawn to determine $\mathrm{NO}_{3}{ }^{-}$plus $\mathrm{NO}_{2}{ }^{-}$(NOx) concentrations and lactate at rest (pre-test) and after (post-test) the resistance exercise test. During the resistance exercise test (sessions 3 and 4), the pulmonary gas exchange to determine ventilatory efficiency $\left(\mathrm{VE} \bullet \mathrm{VCO}_{2}{ }^{-1}\right.$ slope and OUES), $\mathrm{PetCO}_{2}$ and heart rate were monitored (Figure 1).

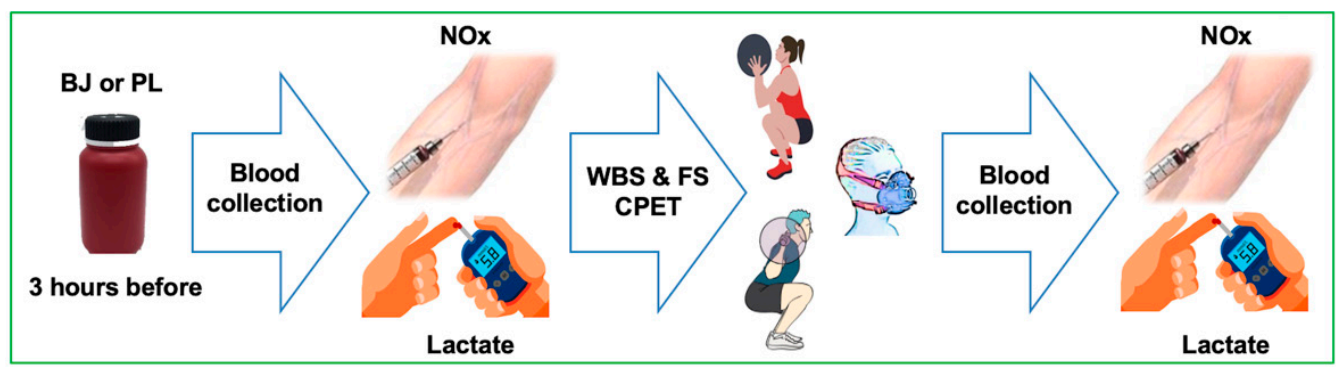

Figure 1. Procedures during the resistance exercise test after beetroot juice (BJ) intake and the placebo (PL) condition of the third and fourth session/BJ or PL randomized, double-blind, crossover design. Abbreviations used: BJ: beetroot juice; CPET: cardiopulmonary exercise test; FS: full squat; NOx: nitrate plus nitrite; PL: placebo; WBS: wall ball shots.

\subsection{Participants}

Eleven male athletes well-trained in resistance exercises were recruited for the study (age $=29.2 \pm 3.7$ years; height $=175.1 \pm 6.3 \mathrm{~cm}$; body mass $=78.9 \pm 5.4 \mathrm{~kg}$ ). The inclusion criteria included: no musculoskeletal injuries and/or diseases; more than two years of experience in resistance training; 1RM in FS equal to or greater than $120 \mathrm{~kg}$; a regional, national and/or international competition level; no smoking; no consumption of any other supplement at the time of the study; no consumption of drugs or medication. The sample size was determined from the results of a pilot study involving 10 well-trained students. The calculation of the sample size was carried out as follows: $\alpha=0.05$ ( $5 \%$ probability of a type I error) and $1-\beta=0.80$ (80\% power).

Informed written consent for participation was gained from all participants. Approval was granted by the Ethics Committee of the TecnoCampus Pompeu Fabra University (IRB approval 56/2019) according to the principles and policies of the Declaration of Helsinki for research in humans. 


\subsection{Diet Control and Beetroot Juice Intake}

A nutrition professional controlled the BJ and PL intake and the diet according to the guidelines established in previous studies $[34,35]$. The diet control was established in a food diary $48 \mathrm{~h}$ before sessions 3 and 4 . All participants followed a similar diet $48 \mathrm{~h}$ before starting the resistance exercise test consisting of $\sim 60 \%$ carbohydrates (5.5 g carbohydrate per $\mathrm{kg}$ ), $25 \%$ lipids and $15 \%$ protein. The diet was registered by the participants $48 \mathrm{~h}$ before the first and the second experimental test. The same diet was replicated before both sessions (BJ and PL). Compliance with the dietary instructions was corroborated by consulting the diaries of the participants. Participants avoided foods with a high $\mathrm{NO}_{3}{ }^{-}$ content at least $72 \mathrm{~h}$ prior to the test sessions. Therefore, a food list was provided to all participants (beetroot, spinach, arugula, lettuce, celery, parsley, turnip, endives, leak, cabbage). Furthermore, the ingestion of alcohol, caffeine (except breakfast coffee) or other supplements was strictly prohibited to avoid any interaction with the BJ. Participants were requested to abstain from chewing gum, eating sweets, using a mouthwash or brushing their teeth (chlorhexidine or xylitol) $24 \mathrm{~h}$ before the study [36]. Participants were advised of the possible side effects of ingesting BJ such as gastrointestinal symptoms and a red appearance of feces and urine.

As in a previous study [34], BJ or the PL was ingested $3 \mathrm{~h}$ before the start of sessions 3 and 4 . The participants were provided with a randomly assigned garnet red plastic bottle containing $140 \mathrm{~mL}$ of BJ Beet-It-Pro Elite Shot concentrate $\left(\sim 12.8 \mathrm{mmol}, \sim 808 \mathrm{mg} \mathrm{NO}_{3}{ }^{-}\right)$ (Beet IT; James White Drinks Ltd., Ipswich, UK) or the PL. The PL beverage was prepared by dissolving $2 \mathrm{~g}$ of powdered $\mathrm{BJ}\left(\sim 0.01 \mathrm{mmol}, 0.620 \mathrm{mg}\right.$ of $\mathrm{NO}_{3}{ }^{-}$, Experience-Naturgreen, Murcia, Spain) in a liter of mineral water by a nutrition professional. Lemon juice was added to simulate the flavor of the commercial drink.

\subsection{Resistance Exercise Tests}

Resistance exercise tests were carried out according to the guidelines established in a previous study [34]. A 1RM test was executed in a FS exercise to determine the loading intensity at $50 \%$ of $1 \mathrm{RM}$ in each participant (session 2). After a general and specific warmup, an incremental test using increasing weights with an Olympic bar was performed to determine 1RM in a FS (in $\mathrm{kg}$ ) exercise. The 1RM test was considered as the highest weight lifted by each participant. A 4 min rest was established between each set.

In sessions 3 and 4, resistance exercise tests were executed for the comparison of the two experimental conditions (BJ and the PL). For this purpose, two weightlifting exercises were selected: wall ball shots (WBS) and a FS. The resistance exercise test consisted of repeating the same routine twice. The first routine consisted of $90 \mathrm{~s}$ of WBS plus $60 \mathrm{~s}$ of FS with a 3 min rest between both exercises. The second routine consisted of WBS for 90 s plus FS for $60 \mathrm{~s}$ without a rest between the two exercises. A 3 min rest was applied between both routines. The same routine with and without a rest was selected to demonstrate the possible ergogenic effect of NOx during a rest under more aerobic conditions. We previously demonstrated that $\mathrm{BJ}$ increased performance to a greater extent than a placebo when a rest was established between exercises. Without a rest between exercises, the anaerobic conditions of the routine increased and there was no ergogenic effect of BJ [34].

The FS exercise was executed with free weight at a loading intensity of $50 \%$ of $1 \mathrm{RM}$. The WBS were executed with a $10 \mathrm{~kg}$ medicine ball. The performance goal was to achieve the highest number of repetitions in each routine. The resistance exercise performance was assessed by the total weight lifted (in $\mathrm{kg}$ ). The weight lifted was computed as the load lifted (in $\mathrm{kg}$ ) multiplied by the number of repetitions performed during the two experimental conditions.

Participants did not perform high intensity physical exercise from $72 \mathrm{~h}$ before the test sessions. Participants abstained from physical exercise during the $24 \mathrm{~h}$ prior to beginning each test session. 


\subsection{Plasma NOx Concentrations}

Blood samples were drawn from the antecubital vein in a $10 \mathrm{~mL}$ EDTA Vacutainer tube. Plasma was then obtained, centrifuged at $2500 \times g$ for $15 \mathrm{~min}$, aliquoted and stored at $-80{ }^{\circ} \mathrm{C}$ until the posterior analysis.

$\mathrm{NO}_{3}{ }^{-}$plus $\mathrm{NO}_{2}{ }^{-}$concentrations (NOx) were measured in plasma previously centrifuged at $14,000 \times g$ for $60 \mathrm{~min}$ and ultrafiltered by a $10 \mathrm{kDa}$ cutoff filter (Millipore-Merck, Darmstadt, Germany). $\mathrm{NO}_{3}{ }^{-}$was converted to nitrite using $\mathrm{NO}_{3}{ }^{-}$reductase and the total $\mathrm{NO}_{2}{ }^{-}$amount was measured by the Griess reaction using a colorimetric assay kit (Cayman Chemical Co., Ann Arbor, MI, USA). Values were expressed as NOx $\mu \mathrm{M}$ of plasma.

\subsection{Pulmonary Gas Exchange}

Pulmonary gas exchange data were recorded during the resistance exercise test (sessions 3 and 4) using a breath-by-breath open-circuit gas analyzer (Ergostik, Geratherm Respiratory, Bad Kissingen, Germany) that was calibrated before each test according to the manufacturer's instructions. $\mathrm{VO}_{2}, \mathrm{VE}, \mathrm{VCO}_{2}$, the respiratory exchange ratio (RER) and $\mathrm{PetCO}_{2}$ were monitored. The heart rate was checked every $5 \mathrm{~s}$ by telemetry (Polar Electro OY, Kempele, Finland).

Ventilatory efficiency was calculated as follows [23]:

$\mathrm{The} \mathrm{VE} \bullet \mathrm{VCO}_{2}{ }^{-1}$ slope was established as the slope of the relationship between VE and $\mathrm{VCO}_{2}$.

The OUES was determined as the relationship between $\mathrm{VO}_{2}$ and the logarithm of the VE. $\mathrm{VO}_{2}=\mathrm{a} \log _{10} \mathrm{VE}+\mathrm{b}$.

\subsection{Blood Lactate}

Blood lactate concentrations were assessed as in previous studies $[34,37,38]$. The analyzer Lactate ProTM 2 (Arkray Factory Inc., KDK Corporation, Shiga, Japan) was used to determine blood lactate concentrations. Lactate ProTM 2 has shown excellent reliability and accuracy [39]. Blood samples were acquired from the index finger of the left hand.

\subsection{Statistical Analysis}

The normal distribution of the data was examined by the Shapiro-Wilk test. Data were presented as mean and standard deviation (SD) and mean and confidence intervals (95\% $\mathrm{CI}$ ). To identify significant differences between the experimental groups (BJ vs. the PL), a two-way analysis of variance (ANOVA) with repeated measures was applied (experimental condition $\bullet$ time). When appropriate, Bonferroni adjustments were applied for multiple comparisons. The magnitude of the response to both experimental conditions was estimated by a partial eta-squared $\left(\eta_{p}{ }^{2}\right)$. The scale for classification of $\eta_{p}{ }^{2}$ was $0.10=$ small, $0.25=$ medium, $0.40=$ large [40]. The statistical power (SP) was calculated. A power analysis indicated that a sample size of 10 was necessary to provide a statistical power of 0.80 or greater for the total weight lifted and ventilatory efficiency data.

Intraclass correlation coefficients (ICCs) and coefficients of variation (CVs) percentages were used to determine the relative and absolute reliability of the cardiorespiratory variables. The significance was set at $p<0.05$. All statistical tests were performed using the software package SPSS version 25.0 for Mac (SPSS Inc., Chicago, IL, USA).

\section{Results}

The exercises and dietary practices were maintained according to the exercise and dietary guidelines. BJ and the PL were drunk at the scheduled time. Participants were blinded to the intake condition. All participants were not able to distinguish between BJ and the PL condition during the first session. Three athletes were suspicious about the intake of the PL. The dietary BJ was well-tolerated by all participants; however, a few participants had beeturia (red urine) and red stools after BJ intake. All participants did not have beeturia and red stools after the PL intake. Plasma NOx levels were increased after BJ intake $(397.63 \mu \mathrm{M})$ compared with the PL $(31.15 \mu \mathrm{M})(p<0.001)$. 
The reliability of the measurements was assessed in cardiorespiratory variables. ICCs for $\mathrm{VO}_{2}, \mathrm{VE}, \mathrm{VCO}_{2}$ and $\mathrm{PetCO}_{2}$ were significant $(p<0.001)$. ICCs were $0.98(\mathrm{CI} 95 \%$ : 0.97-0.99) for $\mathrm{VO}_{2}, 0.97$ (CI 95\%: 0.94-0.98) for $\mathrm{VE}, 0.93$ (CI 95\%: 0.87-0.96) for $\mathrm{VCO}_{2}$ and 0.97 (CI 95\%: 0.95-0.98) for $\mathrm{PetCO}_{2}$. The $\mathrm{CVs}$ were $4.4 \%$ for $\mathrm{VO}_{2}, 6.4 \%$ for $\mathrm{VE}, 5.3 \%$ for $\mathrm{VCO}_{2}$ and $3.1 \%$ for $\mathrm{PetCO}_{2}$.

\subsection{Resistance Exercise Performance}

For the total weight lifted, a significant interaction effect was verified $\left(\mathrm{F}_{(4,40)}=10.30\right.$, $\left.p<0.001, \eta_{\mathrm{p}}{ }^{2}=0.51, \mathrm{SP}=0.99\right)$. Significant effects were found in the time $\left(\mathrm{F}_{(4,40)}=119.42\right.$, $\left.p<0.001, \eta_{\mathrm{p}}{ }^{2}=0.92, \mathrm{SP}=1.00\right)$ and the experimental condition $\left(\mathrm{F}_{(1,10)}=14.00, p=0.004\right.$, $\left.\eta_{\mathrm{p}}{ }^{2}=0.58, \mathrm{SP}=0.92\right)$. A Bonferroni test confirmed a higher weight lifted in the FS exercise after BJ intake than in the PL during the first routine $(p=0.004)$. No significant differences were found in the total weight lifted between the two experimental conditions in the second routine in the FS and WBS exercises $(p>0.05)$ (Figure 2).

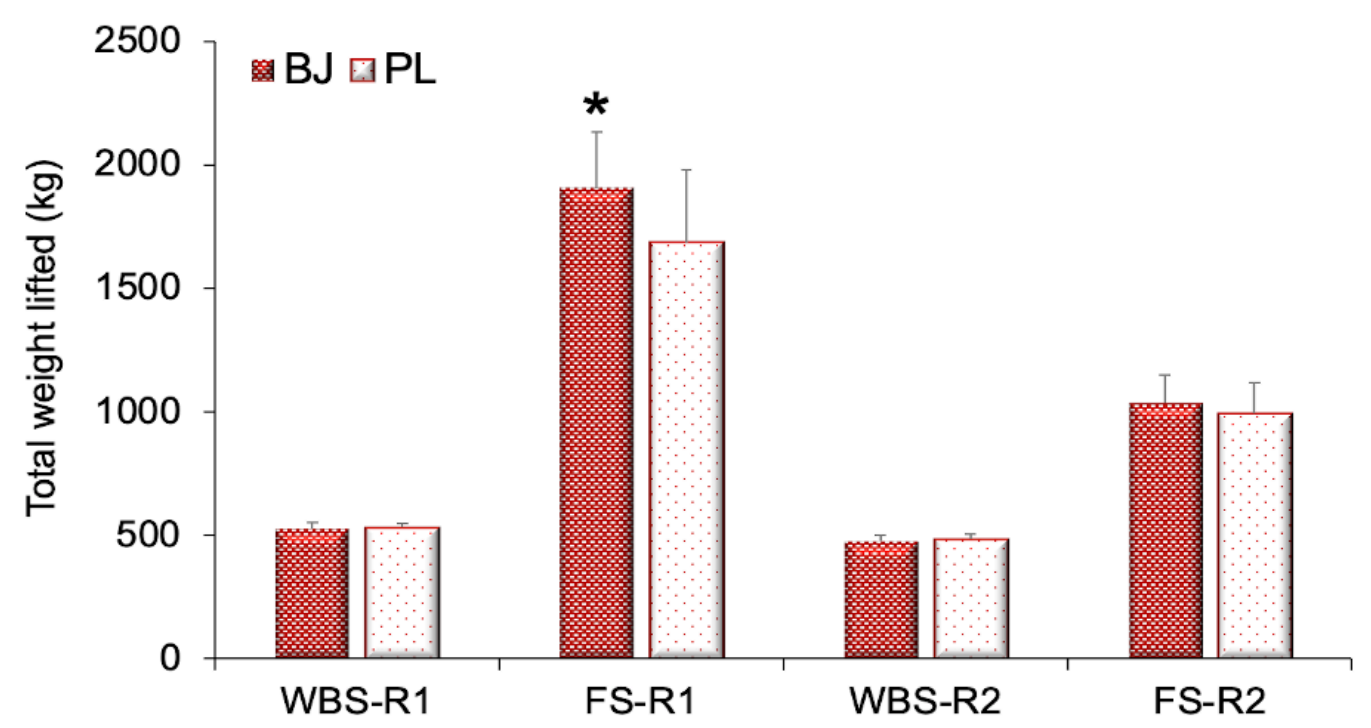

Figure 2. Total weight lifted $(n=11)$. Abbreviations used: BJ: beetroot juice; FS-R1: full squat during the first routine; FS-R2: full squat during the second routine; PL: placebo; WBS-R1: wall ball shots during the first routine; WBS-R2: wall ball shots during the second routine. Data are provided as mean and error bars as $95 \%$ confidence intervals. * Significant increase in the total weight lifted after $\mathrm{BJ}$ intake compared with the PL condition in the first routine (with a 3 min rest) $(p=0.004)$.

\subsection{Ventilatory Efficiency}

For the $\mathrm{VE} \bullet \mathrm{VCO}_{2}{ }^{-1}$ slope, a significant interaction effect was confirmed $\left(\mathrm{F}_{(4,40)}=3.48\right.$, $\left.p=0.016, \eta_{\mathrm{p}}{ }^{2}=0.26, \mathrm{SP}=0.82\right)$. A time effect was found $\left(\mathrm{F}_{(4,40)}=35.48, p<0.001, \eta_{\mathrm{p}}{ }^{2}=0.78\right.$, $\mathrm{SP}=1.00)$; however, no experimental condition effect was detected $(p>0.05)$.

For the OUES, no interaction and experimental condition effects were found $(p>0.05)$ but a time effect was confirmed $\left(\mathrm{F}_{(4,40)}=3.52, p=0.015, \eta_{\mathrm{p}}{ }^{2}=0.26, \mathrm{SP}=0.82\right)$ (Figure $3 \mathrm{~b}$ ).

A Bonferroni test verified that BJ decreased the $\mathrm{VE} \bullet \mathrm{VCO}_{2}{ }^{-1}$ slope during the FS exercise in the first routine $(p=0.047)$ and at rest between the first and the second routine $(p=0.009)$ (Figure 3a). 
(a)

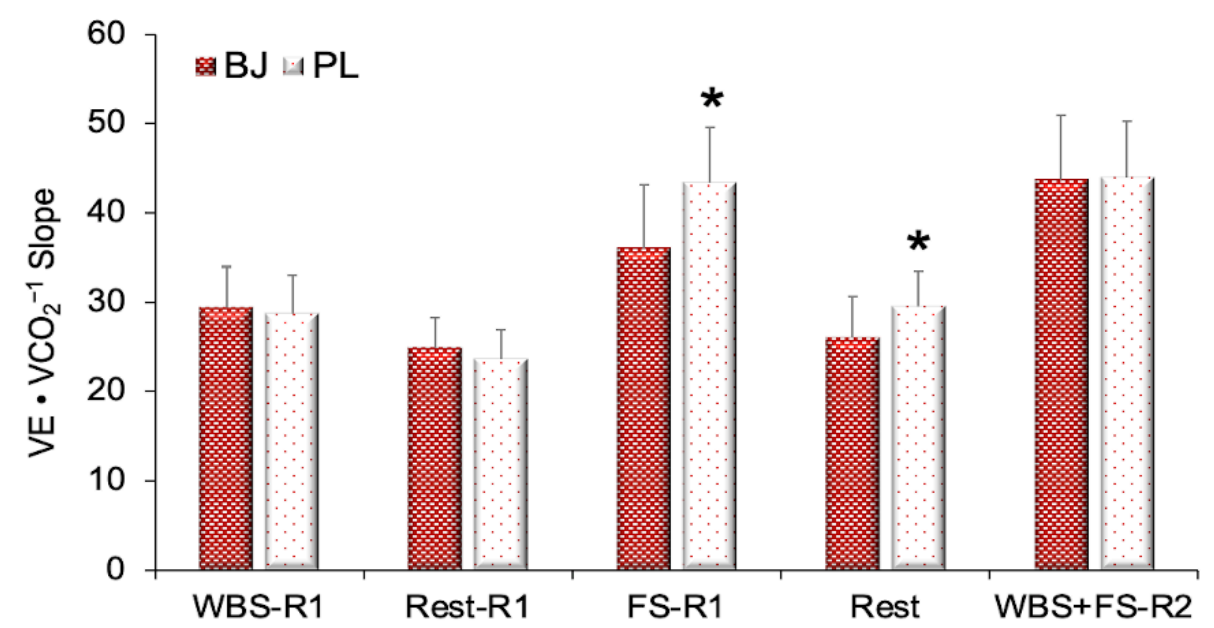

(b)

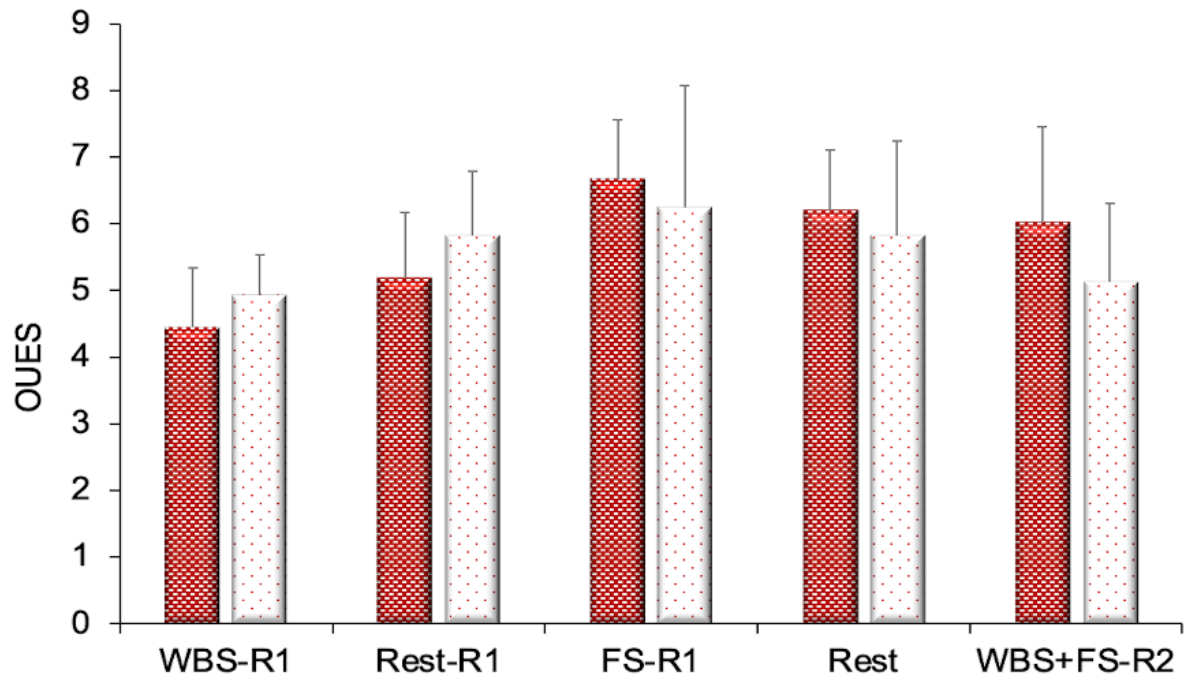

Figure 3. Differences between beetroot juice intake and the placebo $(n=11)$. (a) $\mathrm{VE} \bullet \mathrm{VCO}_{2}{ }^{-1}$ slope (b) OUES. Abbreviations used: BJ: beetroot juice; FS-R1: full squat during the first routine; OUES: oxygen uptake efficiency slope; PL: placebo; WBS-R1: wall ball shots during the first routine; WBS+FSR2: wall ball shots plus full squat during the second routine (without a rest). Data are provided as mean and error bars as $95 \%$ confidence intervals. ${ }^{*}$ Significant increase in the $\mathrm{VE} \bullet \mathrm{VCO}_{2}{ }^{-1}$ slope after the PL intake compared with BJ $(p<0.05)$.

In the $\mathrm{VE} \bullet \mathrm{VCO}_{2}{ }_{2}^{-1}$ slope, $\mathrm{VE}$ and $\mathrm{VCO}_{2}$ were highly correlated $(p<0.001)$ in the two experimental conditions (Figure 4). 
(a)

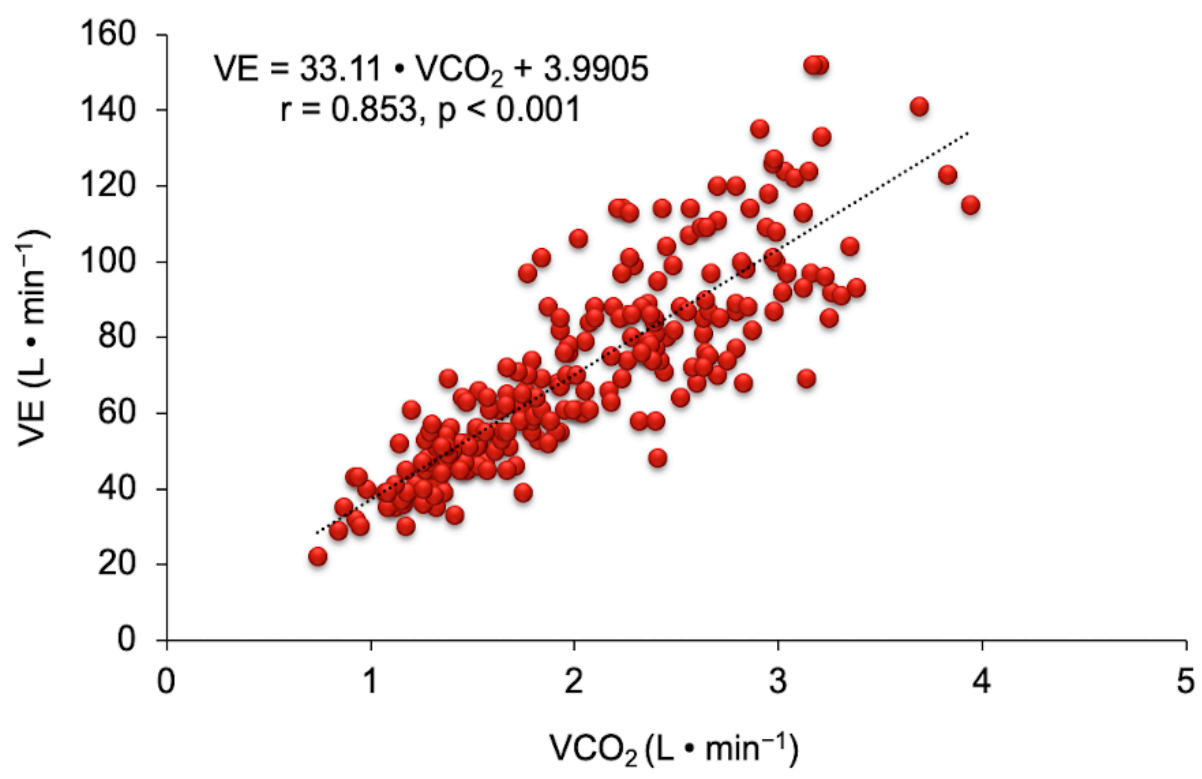

(b)

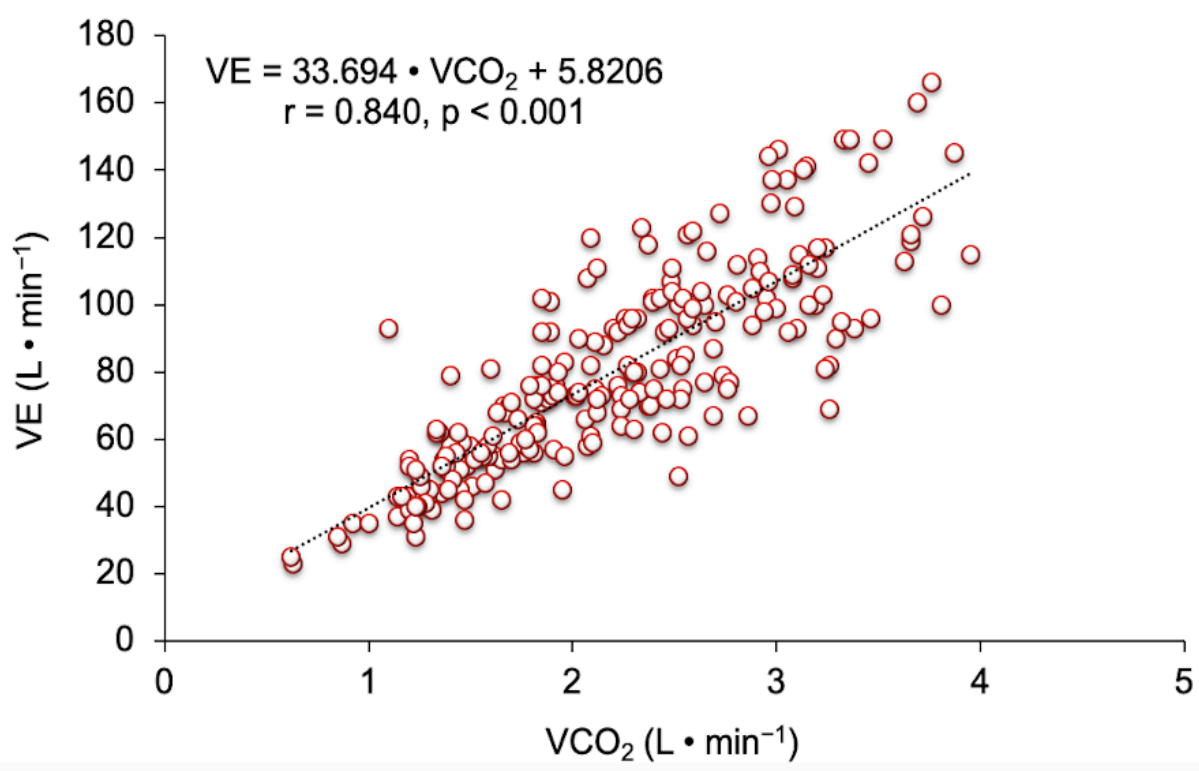

Figure 4. Relationship between ventilation (VE) and carbon dioxide $\left(\mathrm{VE} \bullet \mathrm{VCO}_{2}{ }^{-1}\right.$ slope) after beetroot juice $(\mathbf{a})$ and a placebo $(\mathbf{b})(n=11)$.

Similarly, high correlations $(p<0.001)$ were found between $\mathrm{VO}_{2}$ and $\log _{10} \mathrm{VE}$ in the OUES in the two experimental conditions (Figure 5).

For the PetCO ${ }_{2}$, a significant interaction effect was found $\left(\mathrm{F}_{(4,40)}=3.79, p=0.01, \eta_{\mathrm{p}}{ }^{2}=0.28\right.$, $\mathrm{SP}=0.85)$. Time and experimental condition effects were detected $\left(\mathrm{F}_{(4,40)}=58.58, p<0.001\right.$, $\eta_{\mathrm{p}}^{2}=0.85, \mathrm{SP}=1.00 ; \mathrm{F}_{(1,10)}=25.01, p<0.001, \eta_{\mathrm{p}}{ }^{2}=0.71, \mathrm{SP}=0.99$, respectively). A Bonferroni adjustment corroborated that $\mathrm{BJ}$ increased the $\mathrm{PetCO}_{2}$ during the $\mathrm{FS}$ in the first routine $(p<0.001)$ and at rest between the first and the second routine $(p<0.001)$ (Figure 6). 
(a)

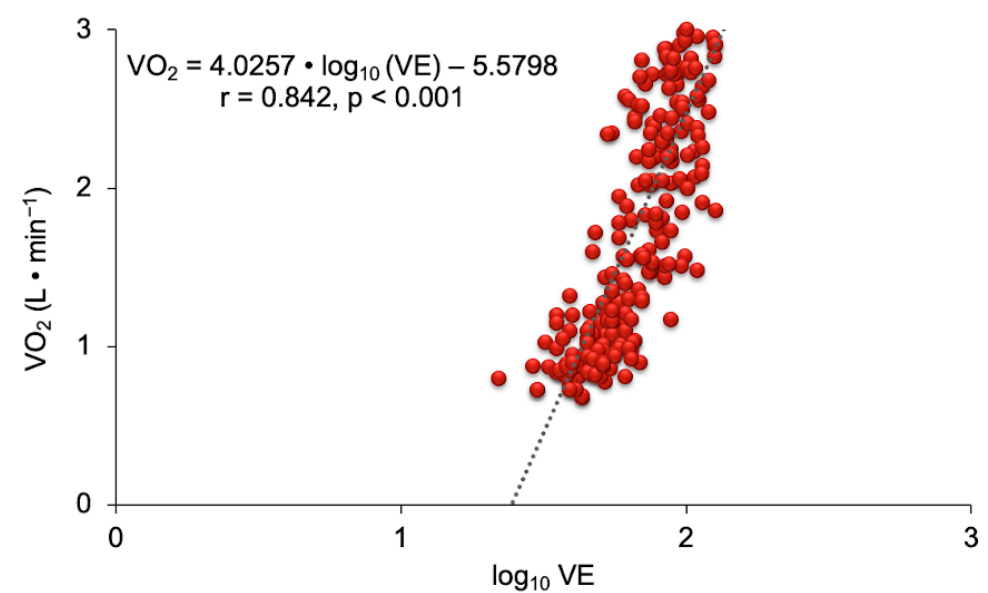

(b)

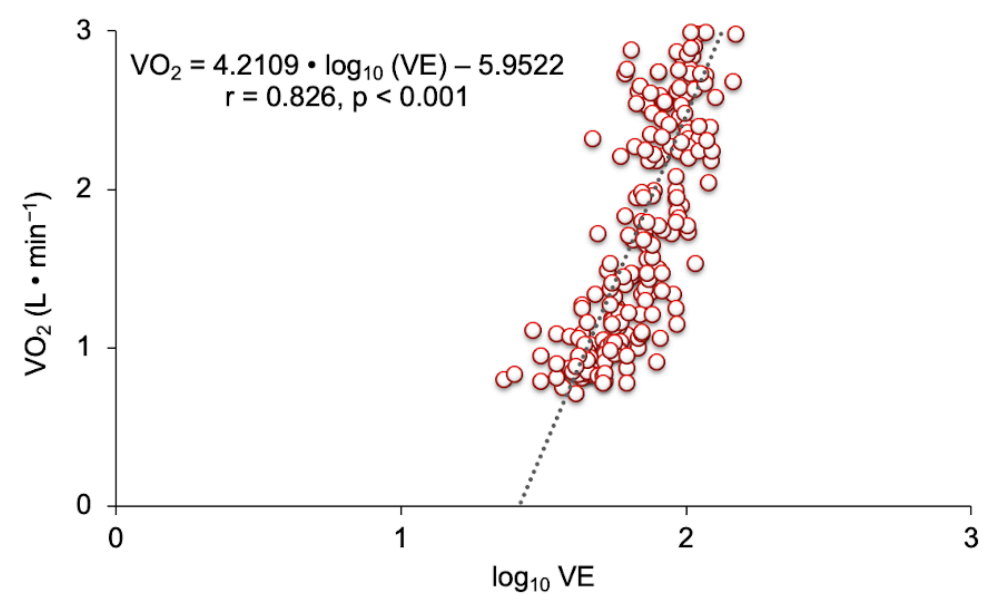

Figure 5. Relationship between oxygen uptake $\left(\mathrm{VO}_{2}\right) \log _{10}$ ventilation (VE) (OUES) after beetroot juice (a) and a placebo (b) $(n=11)$.

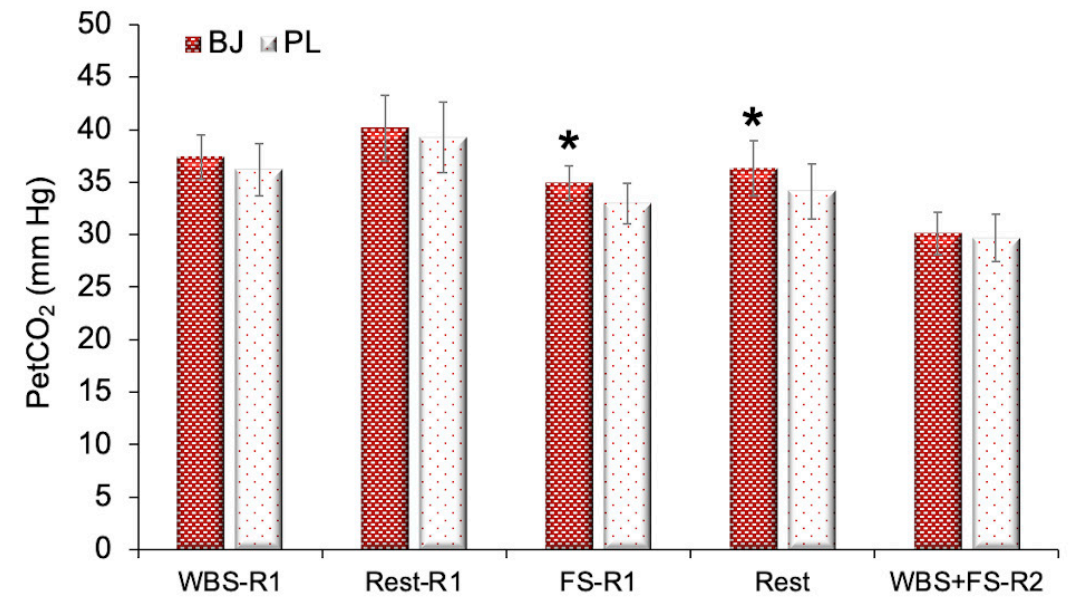

Figure 6. Differences between beetroot juice intake and the placebo in the partial pressure of end-tidal carbon dioxide $\left(\mathrm{PetCO}_{2}\right)(n=11)$. Abbreviations used: BJ: beetroot juice; FS-R1: full squat during the first routine; PL: placebo; WBS-R1: wall ball shots during the first routine; WBS+FS-R2: wall ball shots plus full squat during the second routine (without a rest). Data are provided as mean and error bars as $95 \%$ confidence intervals. ${ }^{*}$ Significant increase in the $\mathrm{PetCO}_{2}$ after $\mathrm{BJ}$ intake compared with PL $(p<0.001)$. 


\subsection{Blood Lactate Concentrations}

For the blood lactate concentrations, no interaction and experimental condition effects were discovered $(p>0.05)$; nevertheless a time effect was detected $\left(\mathrm{F}_{(4,40)}=535.26, p<0.001\right.$, $\eta_{\mathrm{p}}^{2}=0.98, \mathrm{SP}=1.00$ ).

\section{Discussion}

The principal finding of this study was that $\mathrm{BJ}$ intake improved the total weight lifted, the $\mathrm{VE} \bullet \mathrm{VCO}_{2}{ }^{-1}$ slope and the $\mathrm{PetCO}$ in the FS exercise during the first routine and during the rest between both routines in well-trained athletes; conversely, increased plasma NOx concentrations had no effect on the OUES and did not improve the resistance exercise performance, the $\mathrm{VE} \bullet \mathrm{VCO}_{2}{ }^{-1}$ slope and the $\mathrm{PetCO}_{2}$ when anaerobic conditions were increased during the second routine. Consistent with the experimental hypothesis, we suggest a causal physiological relationship between the $\mathrm{VE} \bullet \mathrm{VCO}_{2}{ }^{-1}$ slope, the $\mathrm{PetCO}_{2}$ and the total weight lifted in the FS exercise after acute BJ intake when a rest between WBS and FS exercises was applied.

The assessment of the $\mathrm{VE} \bullet \mathrm{VCO}_{2}{ }^{-1}$ slope and the OUES in resistance exercises has not received the same consideration as, for instance, in endurance exercises. We previously demonstrated that resistance exercise induced a similar $\mathrm{VE} \bullet \mathrm{VCO}_{2}{ }^{-1}$ slope and OUES compared with endurance exercise at the same metabolic intensity (lactate threshold intensity). Rests between sets during a resistance exercise test was a key factor to detecting similar ventilatory efficiency in a resistance exercise and an endurance exercise at a moderate intensity [23]. In other study, we also showed that acute BJ intake improved performance when a rest between exercises was established during a high intensity resistance exercise test in severe anaerobic metabolism [34].

In this study, there was a significant trend to decrease the $\mathrm{VE} \bullet \mathrm{VCO}_{2}{ }^{-1}$ slope after BJ intake compared with the PL $(p=0.06)$ during both routines although the $\mathrm{VE} \bullet \mathrm{VCO}_{2}{ }^{-1}$ slope only declined significantly with a rest between exercises coinciding with improvements in FS performance (first routine). Again, we suspect that the effect of increased plasma NOx levels during the rest between exercises was crucial for improving the $\mathrm{VE} \bullet \mathrm{VCO}_{2}{ }^{-1}$ slope and, consequently, the FS performance during the first routine. During the resistance exercise in severe anaerobic conditions (second routine without a rest), increased circulating plasma NOx levels did not alter ventilatory efficiency and performance.

$\mathrm{NO}$ is a powerful vasodilator $[41,42]$ that enhances blood flow under low levels of oxygen and acidic environments [43]. Blood lactate concentrations in both experimental conditions $\left(\sim 18 \mathrm{mmol} \bullet \mathrm{L}^{-1}\right)$ confirmed an acidic environment under severe anaerobic conditions with low oxygen availability. High intensity exercise induces the formation of lactate, $\mathrm{VCO}_{2}$ and hydrogen ions $\left[\mathrm{H}^{+}\right]$causing intracellular acidosis [44]. The $\mathrm{VCO}_{2}$ is a consequence of augmented mitochondrial production. The accumulation of lactate and $\left[\mathrm{H}^{+}\right]$is mainly due to intracellular glycolysis $[45,46]$ and both are liberated into extracellular fluid $[47,48]$. Severe metabolic acidosis induced by high intensity exercises can preserve increased muscle dysfunction by inhibiting mitochondrial activity. In response to increased acidosis, physiological mechanisms to clear lactic acid are based on an increased ventilatory rate to clear accumulated $\mathrm{VCO}_{2}[49,50]$.

In this anaerobic environment, it was expected that there would be an elevated $\mathrm{VE} \bullet \mathrm{VCO}_{2}{ }^{-1}$ slope in response to adequate VE and poor perfusion (VE/perfusion mismatching). Compared with other studies, the mean values of the $\mathrm{VE} \bullet \mathrm{VCO}_{2}{ }^{-1}$ slope (BJ, 31.9; PL, 33.8) and the OUES (BJ, 5.7; PL, 5.6) were worsened in our athletes than in highly trained athletes $\left(\mathrm{VE} \bullet \mathrm{VCO}_{2}{ }^{-1}\right.$ slope, $\sim 28$; OUES, 3.8) [2] and than in healthy people

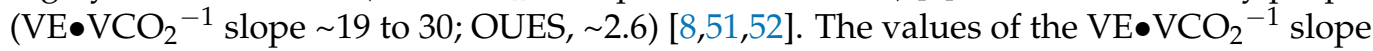
exceeding 34 have been used as a reference to determine ventilatory impairment in diseases $[53,54]$ or to indicate an inefficiency of the respiratory system [51]. The $\mathrm{VE} \bullet \mathrm{VCO}_{2}{ }^{-1}$ slope was worsened in the FS exercise during the first routine $(\mathrm{BJ}=36, \mathrm{PL}=43.3$ ) and the second routine (BJ, 43.7; PL, 43.9) as the anaerobic environment was raised (Figure 3). The obvious difference in the $\mathrm{VE} \bullet \mathrm{VCO}_{2}{ }^{-1}$ slope between the two experimental conditions was 
produced in the FS exercise during the first routine and in the subsequent recovery time. Theoretically, VE/perfusion mismatching was aggravated in the PL group during the FS exercise (first routine), coinciding with a decrease in weightlifting performance.

A rational explanation for the coincident improvements in the $\mathrm{VE} \bullet \mathrm{VCO}_{2}{ }^{-1}$ slope and exercise performance during the first routine (with a rest) after $\mathrm{BJ}$ intake could be linked to the biochemical and physiological properties of $\mathrm{NO}$. An elevated $\mathrm{VE} \bullet \mathrm{VCO}_{2}{ }^{-1}$ slope was verified in both experimental groups (BJ and the PL); therefore, the mismatching of perfusion/VE was increased during the high intensity resistance exercise in both experimental groups [55]. This physiological event would probably worsen the pulmonary gas exchange by reducing the compliance of the alveoli and by compressing the small blood vessels. As a result, uneven air and blood flow distribution would be expected in the lungs [56]. A 3 min rest between the WBS and FS exercises could have induced a faster $\mathrm{NO}_{3}{ }^{-}-\mathrm{NO}_{2}{ }^{-}$conversion to $\mathrm{NO}$ after $\mathrm{BJ}$ intake. We suggest that $\mathrm{NO}$ could have contributed to an increased blood flow and pulmonary vasodilation reversing a possible vasoconstriction $[57,58]$ especially during a rest. Consequently, the efficiency of the pulmonary gas exchange could be improved by decreasing VE for a given $\mathrm{CO}_{2}$ output and arterial $\mathrm{PCO}_{2}$ [23] after increased plasma NOx concentrations. Therefore, improvements in resistance exercise performance after $\mathrm{BJ}$ intake could be related to the matching of $\mathrm{VE} /$ perfusion when a rest period is applied between exercises.

The effect of dietary $\mathrm{NO}_{3}{ }^{-}$intake on the $\mathrm{VE} \bullet \mathrm{VCO}_{2}{ }^{-1}$ slope and the exercise performance remains controversial. Several studies have proposed that ventilatory efficiency was unchanged in cardiorespiratory diseases after acute dietary $\mathrm{NO}_{3}{ }^{-}$intake; however, exercise performance was improved in patients with heart failure but not in patients with chronic obstructive pulmonary disease [59,60]. Exogenous NO precursors have been confirmed to reduce the $\mathrm{VE} \bullet \mathrm{VCO}_{2}{ }^{-1}$ slope in patients with systolic heart failure [26]. Unfortunately, our results cannot be discussed in relation with studies in well-trained athletes because the $\mathrm{VE} \bullet \mathrm{VCO}_{2}{ }^{-1}$ slope was not evaluated after $\mathrm{BJ}$ ingestion. Given the limited scientific evidence, the possible effect of the increased circulating plasma NOx levels on the $\mathrm{VE} \bullet \mathrm{VCO}_{2}{ }^{-1}$ slope during endurance and resistance exercises in well-trained athletes warrants further investigation.

It is possible that the perceived differences between studies were due to the proposed protocol, the type of exercise and the checkpoints established during the data analysis. It was evident that the aerobic-anaerobic conditions and the established rest elicited a varied response of the $\mathrm{VE} \bullet \mathrm{VCO}_{2}{ }^{-1}$ slope throughout the test. $\mathrm{BJ}$ intake produced an ergogenic effect at specific times depending on the anaerobic conditions of the resistance exercise.

A novel finding observed in this study was that the $\mathrm{VE} \bullet \mathrm{VCO}_{2}{ }^{-1}$ slope was reduced to normal values (BJ and $\mathrm{PL}<25$ ) during a rest between exercises and routines in the two experimental conditions; instead, the OUES remained elevated in the two experimental conditions (BJ and $\mathrm{PL}>$ 5.2). Surprisingly, the $\mathrm{VE} \bullet \mathrm{VCO}_{2}{ }^{-1}$ slope decreased during the rest between both routines after $\mathrm{BJ}$ intake. The reduced $\mathrm{VE} \bullet \mathrm{VCO}_{2}{ }^{-1}$ slope was maintained after the improvements in the FS exercise. It appeared that increased plasma NOx levels caused an ergogenic effect on the $\mathrm{VE} \bullet \mathrm{VCO}_{2}{ }^{-1}$ slope during a rest. This strengthened the theory of the possible vasodilator effect of $\mathrm{BJ}$ to regulate $\mathrm{VE}$ to remove $\mathrm{CO}_{2}$, improving the matching of VE/perfusion during a rest.

Finally, the PetCO $\mathrm{O}_{2}$ was evaluated to corroborate the ergogenic effect of $\mathrm{BJ}$ on the $\mathrm{VE} /$ perfusion relationship. It has been demonstrated that the $\mathrm{PetCO}_{2}$ decreased during a high intensity exercise coinciding with a reduced blood flow and blood velocity [61,62]. Furthermore, the impairment of the pulmonary blood flow and cardiac output during exercise and augmented physiological dead space were the key causes for reducing the $\mathrm{PetCO}_{2}$ in cardiac diseases $[18,63]$.

Oral nitrate supplementation has shown no effect on the $\mathrm{PetCO}_{2}$ and time trial performance during normoxia and hypoxia conditions in trained male cyclists [64]. Other studies have yielded contradictory results. Lewis et al. verified no significant effect of an exogenous $\mathrm{NO}$ precursor on the $\mathrm{PetCO}_{2}$ and the proportion of physiological dead 
space to tidal volume in patients with systolic heart failure [26]; however, others have found improvements in ventilatory efficiency and the $\mathrm{PetCO}_{2}$ in patients with pulmonary hypertension [20]. There are no studies assessing the behavior of the $\mathrm{PetCO}_{2}$ during high intensity resistance exercises after dietary $\mathrm{NO}_{3}{ }^{-}$intake. We speculated that $\mathrm{BJ}$ improved pulmonary blood flow and cardiac output resulting in better perfusion of the alveoli and increased $\mathrm{PetCO}_{2}$ [20].

This study presents a few limitations that should be considered. Minimal changes in performance and physiological responses are usually observed in well-trained athletes [33]; therefore, the sample size should be increased in future research.

\section{Conclusions}

Acute $\mathrm{BJ}$ intake improved the $\mathrm{VE} \bullet \mathrm{VCO}_{2}{ }^{-1}$ slope and the $\mathrm{PetCO}_{2}$ coinciding with an enhanced resistance exercise performance in well-trained athletes. The positive effect of increased plasma NOx levels on the $\mathrm{VE} \bullet \mathrm{VCO}_{2}{ }^{-1}$ slope and $\mathrm{PetCO}_{2}$ could be induced, at least in part, when the aerobic conditions were gradually recovered during a rest. It is likely, therefore, that a rest after an acute resistance performance plays a key role in improving $\mathrm{NO}_{3}{ }^{-}-\mathrm{NO}_{2}{ }^{-}$conversion to $\mathrm{NO}$ during severe anaerobic exercise with low oxygen availability, enhancing its vasodilator effect at a pulmonary level.

The findings reported here open new lines of research for understanding the physiological mechanisms that link the effects of $\mathrm{NO}$ with lung function and exercise performance during high intensity resistance exercises, especially during a rest.

Author Contributions: N.S.-P., M.G.B. and M.V.G.-C. conceived and designed the experiments; N.S.-P., S.S.-N., L.A.-A., L.M.A., A.P.F., A.G.-F., J.C.-O., X.V., L.M.-R. and M.V.G.-C. performed the experiments; M.G.-F. and M.V.G.-C. analyzed the data; N.S.-P., S.S.-N., L.A.-A., M.G.-F., L.M.A., A.P.F., A.G.-F., J.C.-O., X.V., L.M.-R. and M.V.G.-C. contributed reagents/materials/analysis tools; N.S.-P., M.G.B. and M.V.G.-C. wrote the paper. All authors have read and agreed to the published version of the manuscript.

Funding: This research was funded by the TECNOCAMPUS FOUNDATION.

Institutional Review Board Statement: This investigation was approved by the Ethics Committee of the TecnoCampus, Pompeu Fabra University (IRB approval 56/2019, 24 November 2017) and was performed according to the principles and policies of the Declaration of Helsinki.

Informed Consent Statement: Informed written consent for participation was gained from all participants.

Data Availability Statement: Data are presented in the manuscript; further information available upon request.

Acknowledgments: The authors would like to thank the participants involved in this research for their cooperation.

Conflicts of Interest: The authors declare no conflict of interest.

\section{References}

1. Reindl, I.; Kleber, R.X. Exertional hyperpnea in patients with chronic heart failure is a reversible cause of exercise intolerance. Basic Res. Cardiol. 1996, 91, 37-43. [PubMed]

2. Brown, S.J.; Raman, A.; Schlader, Z.; Stannard, S.R. Ventilatory efficiency in juvenile elite cyclists. J. Sci. Med. Sport 2013, 16, 266-270. [CrossRef]

3. Romer, L.M.; Polkey, M.I. Exercise-induced respiratory muscle fatigue: Implications for performance. J. Appl. Physiol. 2008, 104, 879-888. [CrossRef]

4. Whipp, B.J. The bioenergetic and gas exchange basis of exercise testing. Clin. Chest Med. 1994, 15, 173-192.

5. Hammond, M.D.; Gale, G.E.; Kapitan, K.S.; Ries, A.; Wagner, P.D. Pulmonary gas exchange in humans during exercise at sea level. J. Appl. Physiol. 1986, 60, 1590-1598. [CrossRef] [PubMed]

6. Schaffartzik, W.; Poole, D.C.; Derion, T.; Tsukimoto, K.; Hogan, M.C.; Arcos, J.P.; Bebout, D.E.; Wagner, P.D. VA/Q் distribution during heavy exercise and recovery in humans: Implications for pulmonary edema. J. Appl. Physiol. 1992, 72, $1657-1667$. [CrossRef] 
7. Balady, G.J.; Arena, R.; Sietsema, K.; Myers, J.; Coke, L.; Fletcher, G.F.; Forman, D.; Franklin, B.; Guazzi, M.; Gulati, M.; et al. Clinician's guide to cardiopulmonary exercise testing in adults: A scientific statement from the American heart association. Circulation 2010, 122, 191-225. [CrossRef] [PubMed]

8. Sun, X.G.; Hansen, J.E.; Garatachea, N.; Storer, T.W.; Wasserman, K. Ventilatory efficiency during exercise in healthy subjects. Am. J. Respir. Crit. Care Med. 2002, 166, 1443-1448. [CrossRef] [PubMed]

9. Gavotto, A.; Huguet, H.; Picot, M.C.; Guillaumont, S.; Matecki, S.; Amedro, P. The Ve/Vंco2 slope: A useful tool to evaluate the physiological status of children with congenital heart disease. J. Appl. Physiol. 2020, 129, 1102-1110. [CrossRef] [PubMed]

10. Baba, R.; Nagashima, M.; Goto, M.; Nagano, Y.; Yokota, M.; Tauchi, N.; Nishibata, K. Oxygen uptake efficiency slope: A new index of cardiorespiratory functional reserve derived from the relation between oxygen uptake and minute ventilation during incremental exercise. J. Am. Coll. Cardiol. 1996, 28, 1567-1572. [CrossRef]

11. Guazzi, M.; Adams, V.; Conraads, V.; Halle, M.; Mezzani, A.; Vanhees, L.; Arena, R.; Fletcher, G.F.; Forman, D.E.; Kitzman, D.W.; et al. Clinical recommendations for cardiopulmonary exercise testing data assessment in specific patient populations. Circulation 2012, 126, 2261-2274. [CrossRef]

12. Arena, R.; Myers, J.; Guazzi, M. The clinical and research applications of aerobic capacity and ventilatory efficiency in heart failure: An evidence-based review. Heart Fail. Rev. 2008, 13, 245-269. [CrossRef]

13. Chlif, M.; Chaouachi, A.; Ahmaidi, S. Effect of aerobic exercise training on ventilatory efficiency and respiratory drive in obese subjects. Respir. Care 2017, 62, 936-946. [CrossRef]

14. Grinstein, J.; Sawalha, Y.; Hofmeyer, M.; Sheikh, F.; Rodrigo, M.; Kadakkal, A.; Barnett, C.; Kalantari, S.; Talati, I.; Zaghlol, R.; et al. VE/VCO2 Predicts RV Dysfunction and Mortality after Left Ventricular Assist Device: A Fresh Look at Cardiopulmonary Stress Testing for Prognostication. J. Heart Lung Transplant. 2019, 38, S106-S107. [CrossRef]

15. Fung, E.; Ting Lui, L.; Gustafsson, F.; Yau, F.C.F.; Leung, J.C.S.; Wiklund, P.; Järvelin, M.R.; Macdonald, P.S.; Woo, J. Predicting 10-year mortality in older adults using VO2max, oxygen uptake efficiency slope and frailty class. Eur. J. Prev. Cardiol. 2020. [CrossRef] [PubMed]

16. Da Luz Goulart, C.; dos Santos, P.B.; Caruso, F.R.; Arêas, G.P.T.; Marinho, R.S.; De Faria Camargo, P.; Da Silva Alexandre, T.; Oliveira, C.R.; da Silva, A.L.G.; Mendes, R.G.; et al. The Value of cardiopulmonary exercise testing in Determining Severity in patients with both Systolic Heart failure and COPD open. Sci. Rep. 2020, 10, 4309. [CrossRef]

17. Laveneziana, P.; Agostoni, P.; Mignatti, A.; Mushtaq, S.; Colombo, P.; Sims, D.; Uriel, N.; Jorde, U.P. Effect of Acute $\beta$-blocker Withholding on Ventilatory Efficiency in Patients With Advanced Chronic Heart Failure. J. Card. Fail. 2010, 16, 548-555. [CrossRef]

18. Tanabe, Y.; Hosaka, Y.; Ito, M.; Ito, E.; Suzuki, K. Significance of end-tidal PCO2 response to exercise and its relation to functional capacity in patients with chronic heart failure. Chest 2001, 119, 811-817. [CrossRef] [PubMed]

19. Hansen, J.E.; Ulubay, G.; Chow, B.F.; Sun, X.G.; Wasserman, K. Mixed-expired and end-tidal CO2 distinguish between ventilation and perfusion defects during exercise testing in patients with lung and heart diseases. Chest 2007, 132, 977-983. [CrossRef] [PubMed]

20. Oudiz, R.J.; Roveran, G.; Hansen, J.E.; Sun, X.G.; Wasserman, K. Effect of sildenafil on ventilatory efficiency and exercise tolerance in pulmonary hypertension. Eur. J. Heart Fail. 2007, 9, 917-921. [CrossRef] [PubMed]

21. Salazar-Martínez, E.; Terrados, N.; Burtscher, M.; Santalla, A.; Naranjo Orellana, J. Ventilatory efficiency and breathing pattern in world-class cyclists: A three-year observational study. Respir. Physiol. Neurobiol. 2016, 229, 17-23. [CrossRef] [PubMed]

22. Davis, J.A.; Sorrentino, K.M.; Ninness, E.M.; Pham, P.H.; Dorado, S.; Costello, K.B. Test-retest reliability for two indices of ventilatory efficiency measured during cardiopulmonary exercise testing in healthy men and women. Clin. Physiol. Funct. Imaging 2006, 26, 191-196. [CrossRef] [PubMed]

23. Albesa-Albiol, L.; Serra-Payá, N.; Garnacho-Castaño, M.A.; Cano, L.G.; Cobo, E.P.; Maté-Muñoz, J.L.; Garnacho-Castaño, M.V. Ventilatory efficiency during constant-load test at lactate threshold intensity: Endurance versus resistance exercises. PLoS ONE 2019, 14, e0216824. [CrossRef]

24. Zapol, W.M.; Rimar, S.; Gillis, N.; Marletta, M.; Bosken, C.H. Nitric oxide and the lung. Am. J. Respir. Crit. Care Med. 1994, 149, 1375-1380. [CrossRef] [PubMed]

25. Banning, A.P.; Prendergast, B. Intravenous L-arginine reduces VE/VCO2 slope acutely in patients with severe chronic heart failure. Eur. J. Heart Fail. 1999, 1, 187-190. [CrossRef]

26. Lewis, G.D.; Lachmann, J.; Camuso, J.; Lepore, J.J.; Shin, J.; Martinovic, M.E.; Systrom, D.M.; Bloch, K.D.; Semigran, M.J. Sildenafil improves exercise hemodynamics and oxygen uptake in patients with systolic heart failure. Circulation 2007, 115, 59-66. [CrossRef]

27. Curtis, K.J. Spiral: Augmenting Pulmonary Rehabilitation in Chronic Obstructive Pulmonary Disease: Studies of ACE-Inhibition and Nitrate Supplementation. Ph.D. Thesis, Imperial College London, London, UK, 2017.

28. Hwang, I.-C.; Kim, Y.-J.; Park, J.-B.; Yoon, Y.E.; Lee, S.-P.; Kim, H.-K.; Cho, G.-Y.; Sohn, D.-W. Pulmonary hemodynamics and effects of phosphodiesterase type 5 inhibition in heart failure: A meta-analysis of randomized trials. BMC Cardiovasc. Disord. 2017, 17, 150. [CrossRef]

29. Michelakis, E.; Tymchak, W.; Lien, D.; Webster, L.; Hashimoto, K.; Archer, S. Oral sildenafil is an effective and specific pulmonary vasodilator in patients with pulmonary arterial hypertension: Comparison with inhaled nitric oxide. Circulation 2002, 105, 2398-2403. [CrossRef] [PubMed] 
30. Lepore, J.J.; Maroo, A.; Pereira, N.L.; Ginns, L.C.; Dec, G.W.; Zapol, W.M.; Bloch, K.D.; Semigran, M.J. Effect of Sildenafil on the acute pulmonary vasodilator response to inhaled nitric oxide in adults with primary pulmonary hypertension. Am. J. Cardiol. 2002, 90, 677-680. [CrossRef]

31. Hoon, M.W.; Jones, A.M.; Johnson, N.A.; Blackwell, J.R.; Broad, E.M.; Lundy, B.; Rice, A.J.; Burke, L.M. The effect of variable doses of inorganic nitrate-rich beetroot juice on simulated 2000-m rowing performance in trained athletes. Int. J. Sports Physiol. Perform. 2014, 9, 615-620. [CrossRef]

32. Domínguez, R.; Cuenca, E.; Maté-Muñoz, J.L.; García-Fernández, P.; Serra-Paya, N.; Estevan, M.C.L.; Herreros, P.V.; GarnachoCastaño, M.V. Effects of beetroot juice supplementation on cardiorespiratory endurance in athletes. A systematic review. Nutrients 2017, 9, 43. [CrossRef]

33. Garnacho-Castaño, M.V.; Palau-Salvà, G.; Cuenca, E.; Muñoz-González, A.; García-Fernández, P.; del Carmen Lozano-Estevan, M.; Veiga-Herreros, P.; Maté-Muñoz, J.L.; Domínguez, R. Effects of a single dose of beetroot juice on cycling time trial performance at ventilatory thresholds intensity in male triathletes. J. Int. Soc. Sports Nutr. 2018, 15, 49. [CrossRef]

34. Garnacho-Castaño, M.V.; Palau-Salvà, G.; Serra-Payá, N.; Ruiz-Hermosel, M.; Berbell, M.; Viñals, X.; Gomis Bataller, M.; Carbonell, T.; Vilches-Saez, S.; Pleguezuelos Cobo, E.; et al. Understanding the effects of beetroot juice intake on CrossFit performance by assessing hormonal, metabolic and mechanical response: A randomized, double-blind, crossover design. J. Int. Soc. Sports Nutr. 2020, 17. [CrossRef] [PubMed]

35. Jeukendrup, A.E. High-carbohydrate versus high-fat diets in endurance sports Übersichtsartikel High-carbohydrate versus high-fat diets in endurance sports. Schweizerische Zeitschrift Sport. Sport. 2003, 51, 17-23.

36. Govoni, M.; Jansson, E.Å.; Weitzberg, E.; Lundberg, J.O. The increase in plasma nitrite after a dietary nitrate load is markedly attenuated by an antibacterial mouthwash. Nitric Oxide 2008, 19, 333-337. [CrossRef]

37. Garnacho-Castaño, M.V.; Albesa-Albiol, L.; Serra-Payá, N.; Gomis Bataller, M.; Pleguezuelos Cobo, E.; Guirao Cano, L.; GuodemarPérez, J.; Carbonell, T.; Domínguez, R.; Maté-Muñoz, J.L. Oxygen Uptake Slow Component and the Efficiency of Resistance Exercises. J. Strength Cond. Res. 2018. [CrossRef]

38. Garnacho-Castaño, M.V.; Albesa-Albiol, L.; Serra-Payá, N.; Gomis Bataller, M.; Felíu-Ruano, R.; Guirao Cano, L.; Pleguezuelos Cobo, E.; Maté-Muñoz, J.L. The Slow Component of Oxygen Uptake and Efficiency in Resistance Exercises: A Comparison With Endurance Exercises. Front. Physiol. 2019, 10, 357. [CrossRef]

39. Bonaventura, J.M.; Sharpe, K.; Knight, E.; Fuller, K.L.; Tanner, R.K.; Gore, C.J. Reliability and accuracy of six hand-held blood lactate analysers. J. Sports Sci. Med. 2014, 14, 203-214.

40. Cohen, J. Quantitative methods in psychology: A power primer. Psychol. Bull. 1992, 112, 1155-1159. [CrossRef]

41. Cosby, K.; Partovi, K.S.; Crawford, J.H.; Patel, R.P.; Reiter, C.D.; Martyr, S.; Yang, B.K.; Waclawiw, M.A.; Zalos, G.; Xu, X.; et al. Nitrite reduction to nitric oxide by deoxyhemoglobin vasodilates the human circulation. Nat. Med. 2003, 9, 1498-1505. [CrossRef] [PubMed]

42. Maher, A.R.; Milsom, A.B.; Gunaruwan, P.; Abozguia, K.; Ahmed, I.; Weaver, R.A.; Thomas, P.; Ashrafian, H.; Born, G.V.R.; James, P.E.; et al. Hypoxic modulation of exogenous nitrite-induced vasodilation in humans. Circulation 2008, 117, 670-677. [CrossRef] [PubMed]

43. Erzurum, S.C.; Ghosh, S.; Janocha, A.J.; Xu, W.; Bauer, S.; Bryan, N.S.; Tejero, J.; Hemann, C.; Hille, R.; Stuehr, D.J.; et al. Higher blood flow and circulating NO products offset high-altitude hypoxia among Tibetans. Proc. Natl. Acad. Sci. USA 2007, 104, 17593-17598. [CrossRef] [PubMed]

44. Lühker, O.; Berger, M.M.; Pohlmann, A.; Hotz, L.; Gruhlke, T.; Hochreiter, M. Changes in acid-base and ion balance during exercise in normoxia and normobaric hypoxia. Eur. J. Appl. Physiol. 2017, 117, 2251-2261. [CrossRef] [PubMed]

45. Lindinger, M.I.; McKelvie, R.S.; Heigenhauser, G.J.F. K+ and Lac- distribution in humans during and after high-intensity exercise: Role in muscle fatigue attenuation? J. Appl. Physiol. 1995, 78, 765-777. [CrossRef]

46. Stickland, M.K.; Lindinger, M.I.; Olfert, I.M.; Heigenhauser, G.J.F.; Hopkins, S.R. Pulmonary gas exchange and acid-base balance during exercise. Compr. Physiol. 2013, 3, 693-739. [PubMed]

47. Gladden, L.B. Lactate metabolism: A new paradigm for the third millennium. J. Physiol. 2004, 558, 5-30. [CrossRef] [PubMed]

48. Goodwin, M.L.; Harris, J.E.; Hernández, A.; Gladden, L.B. Blood lactate measurements and analysis during exercise: A guide for clinicians. J. Diabetes Sci. Technol. 2007, 1, 558-569. [CrossRef]

49. Vohwinkel, C.U.; Lecuona, E.; Sun, H.; Sommer, N.; Vadász, I.; Chandel, N.S.; Sznajder, J.I. Elevated CO2 levels cause mitochondrial dysfunction and impair cell proliferation. J. Biol. Chem. 2011, 286, 37067-37076. [CrossRef]

50. Phillips, D.B.; Collins, S.É.; Stickland, M.K. Measurement and Interpretation of Exercise Ventilatory Efficiency. Front. Physiol. 2020, 11, 659. [CrossRef]

51. Brown, S.J.; Brown, J.A. Heart rate variability and ventilatory efficiency. Int. J. Sports Med. 2009, 30, 496-502. [CrossRef]

52. Sun, X.G.; Hansen, J.E.; Stringer, W.W. Oxygen uptake efficiency plateau: Physiology and reference values. Eur. J. Appl. Physiol. 2012, 112, 919-928. [CrossRef]

53. Arena, R.; Guazzi, M.; Myers, J. Prognostic value of end-tidal carbon dioxide during exercise testing in heart failure. Int. J. Cardiol. 2007, 117, 103-108. [CrossRef]

54. Arena, R.; Myers, J.; Hsu, L.; Peberdy, M.A.; Pinkstaff, S.; Bensimhon, D.; Chase, P.; Vicenzi, M.; Guazzi, M. The Minute Ventilation/Carbon Dioxide Production Slope is Prognostically Superior to the Oxygen Uptake Efficiency Slope. J. Card. Fail. 2007, 13, 462-469. [CrossRef] 
55. Hopkins, S.R.; McKenzie, D.C.; Schoene, R.B.; Glenny, R.W.; Robertson, H.T. Pulmonary gas exchange during exercise in athletes I. Ventilation-perfusion mismatch and diffusion limitation. J. Appl. Physiol. 1994, 77, 912-917. [CrossRef] [PubMed]

56. Hopkins, S.R.; Gavin, T.P.; Siafakas, N.M.; Haseler, L.J.; Olfert, I.M.; Wagner, H.; Wagner, P.D. Effect of prolonged, heavy exercise on pulmonary gas exchange in athletes. J. Appl. Physiol. 1998, 85, 1523-1532. [CrossRef] [PubMed]

57. Frostell, C.; Fratacci, M.D.; Wain, J.C.; Jones, R.; Zapol, W.M. Inhaled nitric oxide: A selective pulmonary vasodilator reversing hypoxic pulmonary vasoconstriction. Circulation 1991, 83, 2038-2047. [CrossRef] [PubMed]

58. Frostell, C.G.; Blomqvist, H.; Hedenstierna, G.; Lundberg, J.; Zapol, W.M. Inhaled nitric oxide selectively reverses human hypoxic pulmonary vasoconstriction without causing systemic vasodilation. Anesthesiology 1993, 78, 427-435. [CrossRef]

59. Behnia, M.; Wheatley, C.M.; Avolio, A.; Johnson, B.D. Influence of dietary nitrate supplementation on lung function and exercise gas exchange in COPD patients. Nitric Oxide 2018, 76, 53-61. [CrossRef]

60. Coggan, A.R.; Broadstreet, S.R.; Mahmood, K.; Mikhalkova, D.; Madigan, M.; Bole, I.; Park, S.; Leibowitz, J.L.; Kadkhodayan, A.; Thomas, D.P.; et al. Dietary Nitrate Increases VO2peak and Performance but Does Not Alter Ventilation or Efficiency in Patients With Heart Failure With Reduced Ejection Fraction. J. Card. Fail. 2018, 24, 65-73. [CrossRef]

61. Ellis, L.A.; Ainslie, P.N.; Armstrong, V.A.; Morris, L.E.; Simair, R.G.; Sletten, N.R.; Tallon, C.M.; McManus, A.M. Anterior cerebral blood velocity and end-tidal CO2 responses to exercise differ in children and adults. Am. J. Physiol. Heart Circ. Physiol. 2017, 312, H1195-H1202. [CrossRef]

62. Komiyama, T.; Tanoue, Y.; Sudo, M.; Costello, J.T.; Uehara, Y.; Higaki, Y.; Ando, S. Cognitive Impairment during High-Intensity Exercise: Influence of Cerebral Blood Flow. Med. Sci. Sports Exerc. 2020, 52, 561-568. [CrossRef] [PubMed]

63. Myers, J.; Gujja, P.; Neelagaru, S.; Hsu, L.; Vittorio, T.; Jackson-Nelson, T.; Burkhoff, D. End-tidal CO2 pressure and cardiac performance during exercise in heart failure. Med. Sci. Sports Exerc. 2009, 41, 18-24. [CrossRef] [PubMed]

64. Bourdillon, N.; Fan, J.L.; Uva, B.; Müller, H.; Meyer, P.; Kayser, B. Effect of oral nitrate supplementation on pulmonary hemodynamics during exercise and time trial performance in normoxia and hypoxia: A randomized controlled trial. Front. Physiol. 2015, 6. [CrossRef] [PubMed] 